\title{
A short term analysis of surgical management of umbilical and paraumbilical hernia
}

\author{
Varun Arunagiri, Ragumani Padmanabhan, Parimala Mayandi
}

\begin{tabular}{|c|c|}
\hline \multirow[t]{5}{*}{ ABSTRACT } & $\begin{array}{l}\text { Objective: Umbilical hernia and paraumbilical hernia are ventral herniae that occur in infants and adults. According } \\
\text { to current evidence, mesh repair is the treatment of choice to avoid recurrence. The aim of this study is to analyze } \\
\text { the surgical methods, the types of meshes used, and their benefits. }\end{array}$ \\
\hline & $\begin{array}{l}\text { Material and Methods: A retrospective analysis of patients diagnosed with umbilical hernia and paraumbilical } \\
\text { hernia was performed. The patients' consent was obtained retrospectively. The various surgical techniques and dif- } \\
\text { ferent meshes used were analyzed. Forty-three patients were selected for the study. Of these, } 23 \text { patients underwent } \\
\text { open mesh repair, } 12 \text { patients underwent laparoscopic intraperitoneal onlay mesh repair repair, and eight patients } \\
\text { underwent open intraperitoneal onlay mesh repair repair. The duration of the surgery, mesh used, number of days } \\
\text { of hospital stay, type of anesthesia, and postoperative complications were analyzed. }\end{array}$ \\
\hline & $\begin{array}{l}\text { Results: Of the } 43 \text { patients, the patients who underwent open intraperitoneal onlay mesh repair had shorter posto- } \\
\text { perative hospital stays compared to other methods (median }=1 \text { day; range }=1 \text { to } 2 \text { days). The duration of surgery was } \\
\text { longer for laparoscopic intraperitoneal onlay mesh repair and open mesh repair compared to the open intraperito- } \\
\text { neal onlay mesh repair technique }(p<0.05) \text {. }\end{array}$ \\
\hline & $\begin{array}{l}\text { Conclusion: The open intraperitoneal onlay mesh repair technique had advantages over the other methods for } \\
\text { small-defect umbilical hernia and paraumbilical hernia. The duration of surgery was long for laparoscopic intraperi- } \\
\text { toneal onlay mesh repair compared to open mesh repair and the open intraperitoneal onlay mesh repair technique. } \\
\text { Postoperative complications were insignificant for all three methods. Another advantage of the open intraperitoneal } \\
\text { onlay mesh repair technique was a shorter postoperative hospital stay. }\end{array}$ \\
\hline & Keywords: Open mesh repair, IPOM, open IPOM technique, laparoscopy \\
\hline
\end{tabular}

Cite this paper as: Arunagiri V, Padmanabhan R, Mayandi P. A short term analysis of surgical management of umbilical and paraumbilical hernia. Turk J Surg 2018; 34: 21-23.

Institute of General Surgery, Madras Medical College, Chennai, India

Address for Correspondence Varun Arunagiri

e-mail: surgeonvarun@yahoo.com

Received: 15.08 .2016

Accepted: 03.03.2017

Available Online Date: 04.01.2018

(c) Copyright 2018

by Turkish Surgical Association

Available online at

www.turkjsurg.com

\section{INTRODUCTION}

Umbilical hernia $(\mathrm{UH})$ and paraumbilical hernia $(\mathrm{PUH})$ are ventral herniae that occur in the region of the umbilicus or around the umbilicus (1,2). UH accounts for $10 \%$ of abdominal herniae (3). UH occurs in infants and children, while PUH occurs in adults. UH rarely occurs in adult patients with ascites, obesity, and massive abdominal distention from various causes. There are advantages to the management of UH and PUH using meshes $(3,4)$. The different surgical methods employed in the repair of UH and PUH are open anatomical repair, open mesh repair with different sites of mesh placement (onlay, sublay, and inlay), laparoscopic intraperitoneal onlay mesh repair (IPOM), and open IPOM. The recurrence rate (19\% to 54\%) is greater in anatomical suturing than in mesh repair (5-7). The different sites of deployment of mesh have advantages and disadvantages. In this study, we attempted to analyze two common techniques (open onlay mesh repair and laparoscopic IPOM) and a newer technique, open IPOM, using Ventralex ST for UH and PUH.

\section{MATERIAL AND METHODS}

A retrospective analysis of patients who underwent operations for UH and PUH at the Institute of General Surgery, Madras Medical College, was performed. Patients who underwent surgery for UH and PUH over a period of four months, from November 2015 to February 2016, were chosen for the study. Institutional ethical committee clearance was obtained to collect the data. Informed consent was obtained from the chosen patients. Fifty-four patients were diagnosed with $\mathrm{UH}$ and PUH. Of these, five patients underwent open anatomical suture repair operations as an emergency procedure and another six patients underwent open mesh repair with associated bowel pathology, for which bowel surgery was performed. Excluding these 11 cases, 43 patients with UH and PUH in whom different types of mesh were used were chosen for the study. All the patients were euthyroid before and after surgery. Of the 43 patients who underwent mesh repair, 23 patients underwent open mesh repair using Prolene mesh, 12 patients underwent laparoscopic IPOM using composite dual side mesh (Ethicon Physiomesh flexible composite mesh), and eight underwent open IPOM using a Ventralex ST hernia patch. The surgeons had preferences with regard to the operative methods. All the surgeries were performed by professors and assistant professors and were assisted by senior residents of the institute. The demographic data were analyzed (Table 1). The descriptive data analyzed were the duration of the surgery, the number of days of postoperative hospital stay, the type of anesthesia, and the immediate postoperative complications. A short term follow-up of five months was performed to analyze the immediate recurrence. 


\section{Technique}

In open onlay mesh repair, under regional anesthesia, the sacs of the UH and PUH were dissected all around, and the defect was closed using 1.0 Prolene. Then, a cutaneous flap was raised around the defect for $5 \mathrm{~cm}$, and an onlay Prolene mesh (Bard Davol Inc; Murray Hill, NJ, USA) was placed and fixed to the anterior rectus sheath using 2.0 Prolene; then, a suction drain was placed to avoid seroma to complete the procedure. In the laparoscopic IPOM technique, under general anesthesia, Palmer's point was chosen for a $10 \mathrm{~mm}$ camera port and two $5 \mathrm{~mm}$ working ports were placed using the baseball diamond technique. Composite dual side mesh (Ethicon Physiomesh; Johnson \& Johnson, USA, which has since been withdrawn from the market due to high recurrence) was used in all cases; the defects were closed with 1.0 Prolene, and the composite mesh was fixed using absorbable tackers (Ethicon Securestrap; Johnson \& Johnson, USA). In the open IPOM technique, under regional anesthesia, the UH or PUH sac was opened, the contents were reduced, and the adhesions were released. A composite mesh with a Seprafilm-coated adhesion barrier (Ventralex ST hernia patch; Bard Davol Inc., USA) was placed intraperitoneally; then, the mesh was fixed to the rectus sheath. In all cases, the skin was closed in layers and a sterile dressing was applied.

\section{Statistical Analysis}

Statistical Package for the Social Sciences version 20.0 (IBM Corp.; Armonk, NY, USA) was used for data analysis. Continuous variables were analyzed using the median and range. Other variables were analyzed using the Pearson Chi-Square test. The statistical significance was accepted if the $p<0.05$ (confidence interval 95\%). Independent variables were analyzed using Student's paired t-test, with expected statistical significance if the $p<0.05$. A postoperative complication was defined as any discomfort to a patient who required either conservative management or intervention.

\section{RESULTS}

Forty-three patients were chosen for the study. The median age of the studied population was 48 (range $=40,28$ to 68 ). The sex ratio of the participants was almost equal (male vs. female, $n=21$ vs. $22 ; 48.2 \%$ vs. $51.8 \%)$. There were $69.8 \%$ cases of PUH $(n=30)$ and $30.2 \%$ cases of $\mathrm{UH}(\mathrm{n}=13)$ that were operated with different types of meshes. The number of cases diagnosed as PUH or UH and the different meshes used in the various surgical methods are illustrated in Table 2. The three techniques used by the surgeons for UH and PUH were open onlay mesh repair, laparoscopic IPOM repair, and open IPOM repair. The median size of the defects in both $\mathrm{UH}$ and PUH was $2 \mathrm{~cm}$ (mean $=1.6 \mathrm{~cm}$, $\min 1 \mathrm{~cm}$ to $\max 2 \mathrm{~cm}$ ).

Most of the surgeons preferred the open technique with onlay mesh repair $(53.5 \%, n=23)$ using Prolene mesh. A few surgeons preferred laparoscopic IPOM repair $(27.9 \%, n=12)$, and the remaining surgeons preferred open IPOM repair (18.6\%, $\mathrm{n}=8$ ) using the Ventralex ST hernia patch. The widely followed surgical technique of open onlay mesh repair using Prolene mesh had an average duration of 50.13 minutes (median $=49$ $\mathrm{min}$ ). The mean postoperative stay after open onlay mesh repair was 6.43 days, with a median of 6 days and SD=+1.037. In all the patients, the drainage tubes were retained to avoid seroma. There was an incidence of wound dehiscence $(n=1)$ despite the placement of a drainage tube in an open onlay mesh repair case. In addition to wound dehiscence, postoperative complications included formation of seroma and pain.
Table 1. Characteristics of the study group

$\begin{array}{lc}\text { Characteristics } & \mathrm{n}=43 \\ \mathrm{Age}^{*} \text { (years) } & 44.07(24-64) \\ \text { Gender** } & 21(48.8) \\ \text { Male } & 22(51.2) \\ \text { Female } & \\ \mathrm{BMI}^{* *},\left(\mathrm{~kg} / \mathrm{m}^{2}\right) & 14(32.6) \\ 25 \text { to } 29.9 & 29(67.4) \\ 30 \text { and above } & 30(69.8) \\ \mathrm{PUH}^{* *} & 13(30.2) \\ \mathrm{UH}^{* *} & \end{array}$

BMI: body mass index; UH: umbilical hernia; $\mathrm{PUH}$ : paraumbilical hernia *: mean (range), ${ }^{*}$ : n (\%)

Table 2. Meshes used for paraumbilical hernia and umbilical hernia

Meshes used for PUH and UH

\begin{tabular}{|lccccc|} 
& & \multicolumn{4}{c}{ Mesh used } \\
\hline Diagnosis & IPOM & PROLENE & VST & Total \\
& PUH & 10 & 15 & 5 & 30 \\
& UH & 2 & 8 & 3 & 13 \\
\hline Total & & 12 & 23 & 8 & 43
\end{tabular}

PUH: paraumbilical hernia; UH: umbilical hernia; IPOM: laparoscopic intraperitoneal onlay mesh repair; PROLENE: used for onlay open mesh repair; VST: ventralex ST used in the open mini-IPOM technique

Table 3. Types of meshes used and the preferred type of anesthesia

Meshes used for PUH and UH

\begin{tabular}{|c|c|c|c|c|}
\hline & \multicolumn{4}{|c|}{ Type of Anesthesia } \\
\hline & & $\begin{array}{c}\text { Regional } \\
\text { Anesthesia }\end{array}$ & $\begin{array}{c}\text { General } \\
\text { Anesthesia }\end{array}$ & Total \\
\hline \multirow[t]{3}{*}{ Mesh used } & IPOM & 0 & 12 & 12 \\
\hline & PROLENE & 23 & 0 & 23 \\
\hline & VST & 8 & 0 & 8 \\
\hline Total & 31 & 12 & 43 & \\
\hline
\end{tabular}

PUH: paraumbilical hernia; UH: umbilical hernia; IPOM: laparoscopic intraperitoneal onlay mesh; PROLENE: open onlay mesh repair; VST: open mini-IPOM technique

In laparoscopic IPOM repair, the mean duration of surgery was 68.25 mins (median=67 minutes, range=62 to 80 minutes). Comparing the laparoscopic IPOM technique with open mesh repair, the duration of laparoscopic IPOM surgery was longer ( $p=0.04$ with $\mathrm{Cl}=95 \%$ ); however, there was no significant difference in the number of days of postoperative stay in both techniques. The most common complication of laparoscopic IPOM was pain, which responded well to analgesics.

The open IPOM technique had the shortest duration of postoperative stay and the shortest duration of surgery. The mean and median duration of surgery using this technique was 14 
minutes $(S D=+1.85)$. It was significant $(p=0.001)$ that the open IPOM technique took less time to perform (mean=14 minutes), and the duration of postoperative stay was shorter (median $=1$ day). The postoperative pain was lower (visual analog scale 2) with this method compared to the other techniques. It was evident that the postoperative stay increased as the duration of surgery increased ( $p=0.014$, paired t-test). General anesthesia was preferred by all surgeons for laparoscopic IPOM repair. Both the open IPOM technique and open repair were performed under regional anesthesia (Table 3).

\section{DISCUSSION}

Umbilical hernia and PUH are repaired using mesh to avoid recurrence. In this study, we compared three different surgical techniques employed for $\mathrm{UH}$ and $\mathrm{PUH}$ and the influence of various meshes (Prolene, composite IPOM, composite IPOM for the open IPOM technique) on the duration of the surgery and the postoperative hospital stay. The use of mesh in $\mathrm{UH}$ and $\mathrm{PUH}$ repair results in very low recurrence. (5) The study population had a median defect size of $2 \mathrm{~cm}$ (range 1 to 2). The average BMl of the study population was 30.431 (range 27 to 34). Therefore, the statistical significance of the variables obtained from this study is appropriate for mildly obese patients and for UH and PUH with small defects.

In the open mesh repair onlay technique, the use of Prolene mesh requires more time for flap dissection and mesh reinforcement. The longer the surgery, the more frequent the occurrence of complications, as revealed by the postoperative pain, seroma, and wound gapping experienced following open onlay mesh repair compared to the other methods. The duration of surgery strongly signifies definitive postoperative pain ( $p=0.029$, Pearson Chi-Square test); however, there is no statistical significance with regard to duration of surgery when compared to seroma formation and wound gapping (8).

The laparoscopic IPOM technique is technically demanding. The cost of the mesh is high when compared to the mesh used for open herniae. Generally, postoperative pain due to tackers is less than that due to intracorporeal suturing. However, the open IPOM technique is not technically demanding compared to laparoscopic IPOM. In open mesh repair, the long duration of postoperative stay was attributed to delayed removal of the drainage tube. Although many surgeons favor open onlay mesh repair, the postoperative stay and frequency of seroma formation make it a less attractive option.

The objectives of open IPOM repair are a small incision, minimal dissection, and shorter duration of surgery (9). This technique has statistical significance for shorter postoperative stay (median=1 day); thus, this technique is preferable for patients who desire early recovery to resume their regular activities. In this study, the cost factor and the long-term recurrence rates were not studied. However, many studies have revealed that the open IPOM technique for $\mathrm{UH}$ and PUH has lower recurrence rates (10). The minimal postoperative pain in the open IPOM technique is due to the shorter duration of surgery and minimal tissue handling. As the mesh is anchored in the midline along the linea alba at one or two sites, the postoperative pain is lower compared to that of multiple anchoring in the laparoscopic IPOM and open mesh repair techniques.

\section{Limitations}

An important aspect of the validity of any hernia surgery is the long-term recurrence rate, which is not addressed here. The cost of the different meshes was not analyzed. The influence of the open IPOM technique on UH and PUH with large defects remains to be addressed.

\section{CONCLUSION}

Of the three techniques, open IPOM is the preferred choice for patients with small defects who need to return to work early with less postoperative pain.

Ethics Committee Approval: Ethics committee approval was received for this study from the ethics committee of Institute of General Surgery, Madras Medical College.

Informed Consent: Written informed consent was obtained from patients who participated in this study.

Peer-review: Externally peer-reviewed.

Author Contributions: Concept - V.A.; Design - V.A.; Supervision- R.P.; Resource - R.P.; Materials - V.A.; Data Collection and/or Processing - V.A.; Analysis and/or Interpretation - V.A.; Literature Search - V.A.; Writing Manuscript - P.M.; Critical Reviews - R.P.; Other- P.M.

Conflict of Interest: No conflict of interest was declared by the authors.

Financial Disclosure: The authors declared that this study has received no financial support.

\section{REFERENCES}

1. Schumpelick V. The Umbilical Hernia. Fitzgibbons R J. editors. Recurrent hernia Prevention and treatment. Springer: Verlag Berlin Heidelberg; 2007 p.359-364.

2. Upper GI Surgery Hernia Repairs (groin, umbilicus, wound hernia) Umbilical and Para-Umbilical Hernia In adults, (cited 25th May 2016) Available from: URL:http://www.ruh.nhs.uk/patients/ services/upper_gi/documents/Umbilical_or_Paraumbilical_Hernia_Adults.pdf

3. Aslani N, Brown C J. Does mesh offer an advantage over tissue in the open repair of umbilical hernias? A systematic review and meta-analysis. Hernia. July 2010; 14: 455-462. [CrossRef]

4. Farrow B, Awad S, Berger DH. More than 150 consecutive open umbilical hernia repairs in a major Veterans Administration Medical center. Am J Surg 2008; 196: 647-651. [CrossRef]

5 Arroyo A, Garcia P, Perez F, Andreu J, Candela F, Calpena R. Randomized clinical trial comparing suture and mesh repair of umbilical hernia in adults. Br J Sur 2001; 88: 1321-1323. [CrossRef]

6. Arroyo Sebastián A, Pérez F, Serrano P, Costa D, Oliver I, Ferrer R, et al. Is prosthetic umbilical hernia repair bound to replace primary herniorrhaphy in the adult patients? Hernia 2002; 6: 175-177. [CrossRef]

7. Halm JA, Heisterkamp J, Veen HF, Weidema WF. Long-term followup umbilical hernia repair: are there risk factors for recurrence after simple and mesh repair. Hernia 2005; 9: 334-337. [CrossRef]

8. Lago-Méndez L, Diniz-Freitas M, Senra-Rivera C, Gude-Sampedro F, Rey JM, García-García A. Relationships between surgical difficulty and postoperative pain in lower third molar extractions. J Oral Maxillofac Surg 2007; 65: 979-83. [CrossRef]

9. Berrevoet F, D'Hont F, Rogiers $X$, Troisi R, de Hemptinne B. Open intraperitoneal versus retromuscular mesh repair for umbilical hernias less than 3cm diameter. Am J Surg 2011; 201: 85-90. [CrossRef]

10. Martin DF, Williams RF, Mulrooney T, Voeller GR. Ventralex mesh in umbilical/epigastric hernia repairs: clinical outcomes and complications. Hernia 2008; 12: 379-383.[CrossRef] 